\title{
Zoneamento da Amazônia: uma visão crítica
}

\author{
JUTTA GUTBERLET
}

\section{Riqueza e pobreza na Amazônia}

A AMAZÔNIA É UM BIOMA extremamente complexo e diversificado quando vista sob os pontos de vista social, cultural, ecológico e econômico. É uma região marcada pelas exuberantes e extensas riquezas e belezas naturais e, ao mesmo tempo, pela degradação e devastação ambiental e pelo quadro de pobreza econômica e miséria social sem precedentes. São, portanto, realidades antagônicas e que provocam revolta e conflito.

No presente artigo discutem-se os resultados de um estudo de campo realizado durante três meses nos Estados do Acre, Amazonas e Pará, no fim do ano de 2000, com o objetivo de analisar e avaliar os trabalhos do zoneamento ecológico-econômico em andamento nestes três Estados. Foram entrevistados coordenadores e técnicos responsáveis pela implementação dos trabalhos ligados ao zoneamento em cada Estado, representantes de instituições executoras dos levantamentos e mapeamentos, assim como representantes da sociedade civil organizada - membros de conselhos, sindicatos, cooperativas, associações ou organizações não-governamentais. As visitas aos municípios Presidente Figueiredo, Apuí, Santarém, Itaituba e a algumas comunidades, assim como a participação em oficinas de trabalho também contribuíram na contextualização da realidade local e na avaliação exemplar das estruturas, dos recursos e das organizações envolvidas na produção do zoneamento ecológico-econômico (ver Mapa 1).

O modelo de desenvolvimento prioritariamente adotado hoje na região Amazônica está baseado na extração e exploração insustentável dos recursos naturais, priorizando o lucro imediato para os seus protagonistas. É um modelo fundado na apropriação do espaço e na exploração das riquezas, mas muitas vezes sem considerar culturas locais existentes e dinâmicas naturais que regem os ecossistemas. Este estilo de desenvolvimento traz para a região transformações rápidas com sérias conseqüências socioambientais de médio a longo prazo e em larga escala. A extração predominante das riquezas naturais reflete-se no local em pobreza econômica, exclusão social e degradação ambiental (Hall, 1991), e isso tem aumentado de forma gritante, tanto no meio rural como na cidade. A dinâmica e a intensidade com a qual estão se dando os impactos pedem a urgente reversão dessa situação. Algumas das principais atividades que hoje se destacam por causar grandes impactos ambientais e sociais podem ser vistas na Tabela 1. 


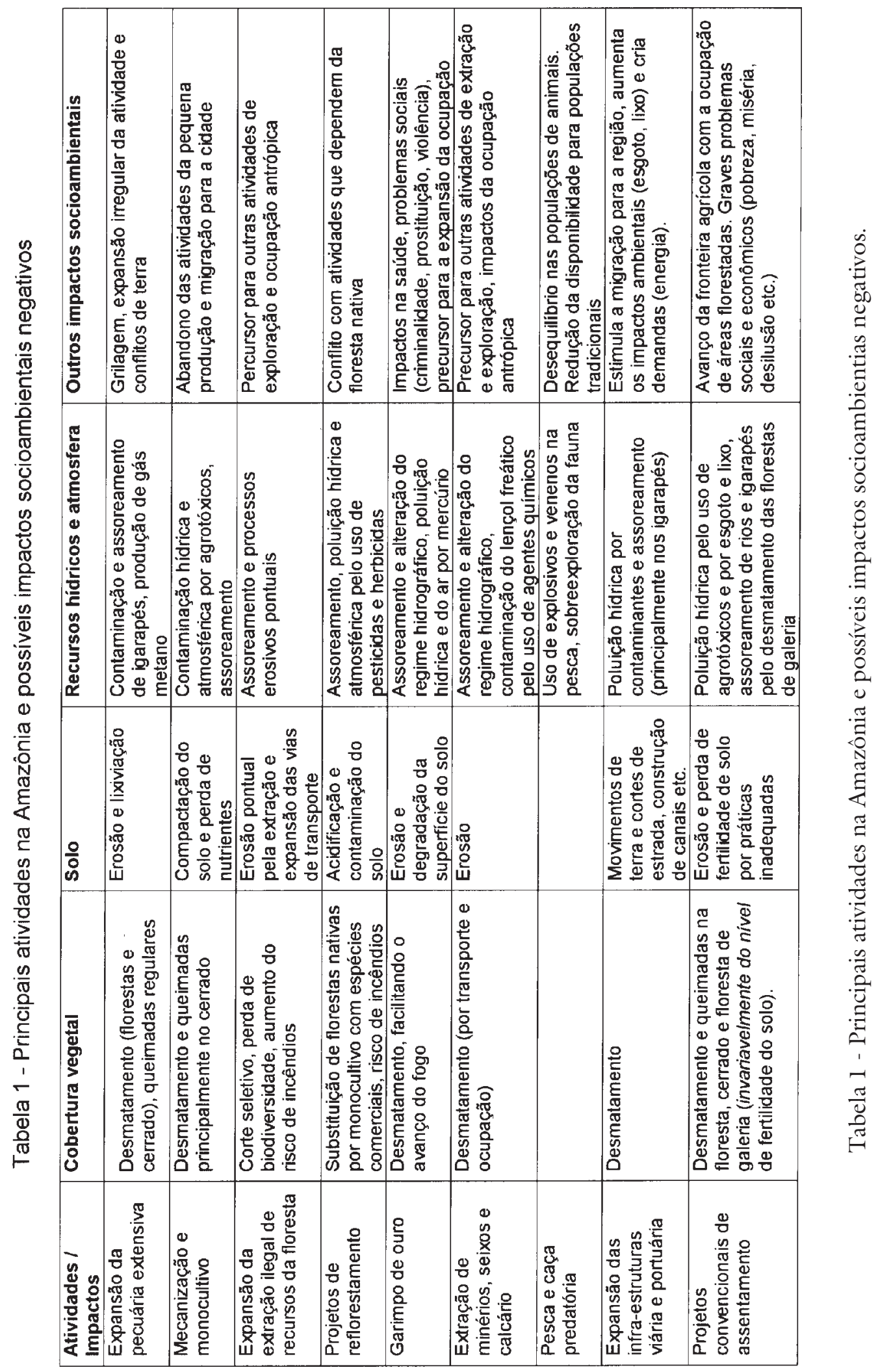




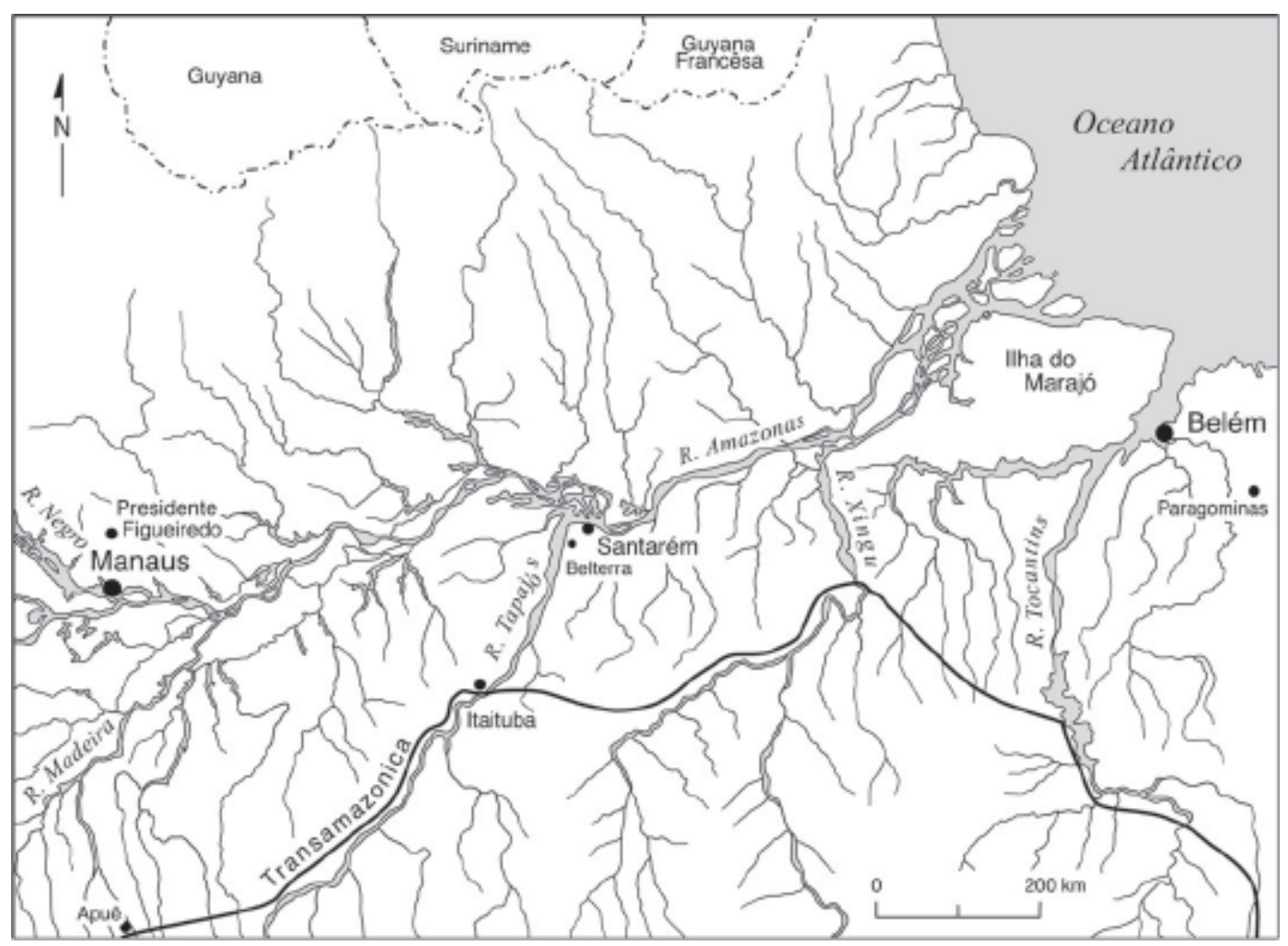

Mapa 1 - Localização de alguns municípios visitados.

Ainda podemos ampliar essa tabela com uma série de outras atividades que estão em expansão na Amazônia, como o tráfico de drogas e o ecoturismo. Percebemos um quadro muito complexo de diversas atividades e interesses, muitas vezes causando sérios impactos ambientais e sociais.

Em nenhum momento as políticas de desenvolvimento do Brasil têm considerado fundamentais as condições específicas do espaço local. Os municípios e as microrregiões sempre foram tratados como receptores de investimentos e executores de políticas já decididas previamente. É uma realidade histórica que as comunidades raramente podem se empenhar na discussão sobre o rumo do desenvolvimento local, resultando, geralmente, em decisões pouco sustentáveis para as comunidades. Uma semelhante prática de pouca participação acontece hoje na elaboração e implementação do zoneamento. Em decorrência, temos uma subutilização das potencialidades locais e muitas vezes até uma interpretação errônea da situação local socioeconômica e física. No decorrer deste artigo será discutida a necessidade de buscar uma nova abordagem, focalizada no desenvolvimento e na participação local.

A intensificação e a expansão do desenvolvimento na Amazônia têm provocado rupturas nas comunidades tradicionais locais, perda da biodiversidade e de biótopos, mudanças climáticas e alterações de médio a longo prazo na estrutura e no funcionamento dos ciclos bioquímicos dos ecossistemas terrestres e 
aquáticos. A atual distribuição da população na região é extremamente desigual, com forte concentração nas cidades e grandes vazios ou áreas de baixíssima densidade no meio rural. Não apenas as cidades grandes como Manaus e Belém, mas também as cidades de médio porte, como Santarém, Presidente Figueiredo ou Paragominas, sofrem da suburbanização. A demanda por infra-estrutura, serviços sociais e saneamento básico tende a não acompanhar o ritmo acelerado do crescimento urbano. Conseqüentemente, uma parte significativa da população não tem suas necessidades básicas atendidas, pois não tem acesso a esses serviços básicos (Browder and Godfrey, 1997).

O crescimento urbano desordenado traz problemas ambientais sérios como o lançamento de esgoto e dos efluentes agroindustriais e industriais não tratados, assim como o depósito de resíduos sólidos em terrenos baldios, rios e igarapés (ver Figura 1). A poluição da água é um problema sério, uma vez que a riqueza dos ecossistemas da Amazônia está baseada na abundância em água doce. A população ribeirinha, a produção intensa nas várzeas assim como a fauna e a flora dependem diretamente da qualidade da água.

Dado este quadro socioambiental, fica evidente a importância do planejamento e da gestão ambiental integrada e compartilhada, adicionando os esforços institucionais para promover a ocupação adequada do espaço e o uso e a proteção dos recursos naturais da região. Já podemos identificar algumas experiências concretas de ONGs, projetos internacionais e programas do governos estadual e local, em que algumas atividades contribuem para o desenvolvimento sustentável. Entre essas, temos as ações dentro da linha de Projetos Demonstrativos (PD/A) do Programa Piloto (PPG7), como o Projeto de Reflorestamento Econômico Consorciado e Adensado no Acre (Reca), a gestão participativa nas reservas extrativistas (Rueda, 1998), a elaboração participativa de planos de gestão e manejo ambiental, por exemplo, a Flona de Tapajós (Almeida et al., 1998), o Parque Nacional do Jaú ou a Reserva de Desenvolvimento Sustentável de Mamirauá (Reis, 1998).

\section{Algumas experiências com o ordenamento territorial}

Faz algumas décadas que o ordenamento territorial na forma do zoneamento está na agenda política do Brasil. Era e ainda é concebido como um importante instrumento de planejamento do espaço urbano e rural. O termo foi introduzido durante a década de 1960, principalmente quando se começou a cristalizar a necessidade de regularização da situação fundiária, que desde o início das ocupações tem sido motivo para sérios conflitos sociais. Com o Estatuto da Terra (Lei n. ${ }^{\circ} 4.504$ de 30/11/64), o zoneamento foi indicado como um dos instrumentos de planejamento para subsidiar ações da Reforma Agrária (Millikan, 1998, p. 19).

No território da Amazônia o Projeto Radam foi finalizado durante os anos de 1970, possibilitando a montagem de uma base de informação sistematizada e detalhada de aspectos da geologia, geomorfologia, cobertura vegetal, dos solos, 
clima e hidrografia da região, utilizando a escala de 1:1.000.000. Ainda hoje, o Projeto Radam é uma das fontes mais ricas de informação geoambiental da região como um todo, reconhecendo, não obstante, limitações impostas pela escala. Conhecer as características biofísicas do espaço era considerado fundamental para poder se apropriar dos recursos naturais.

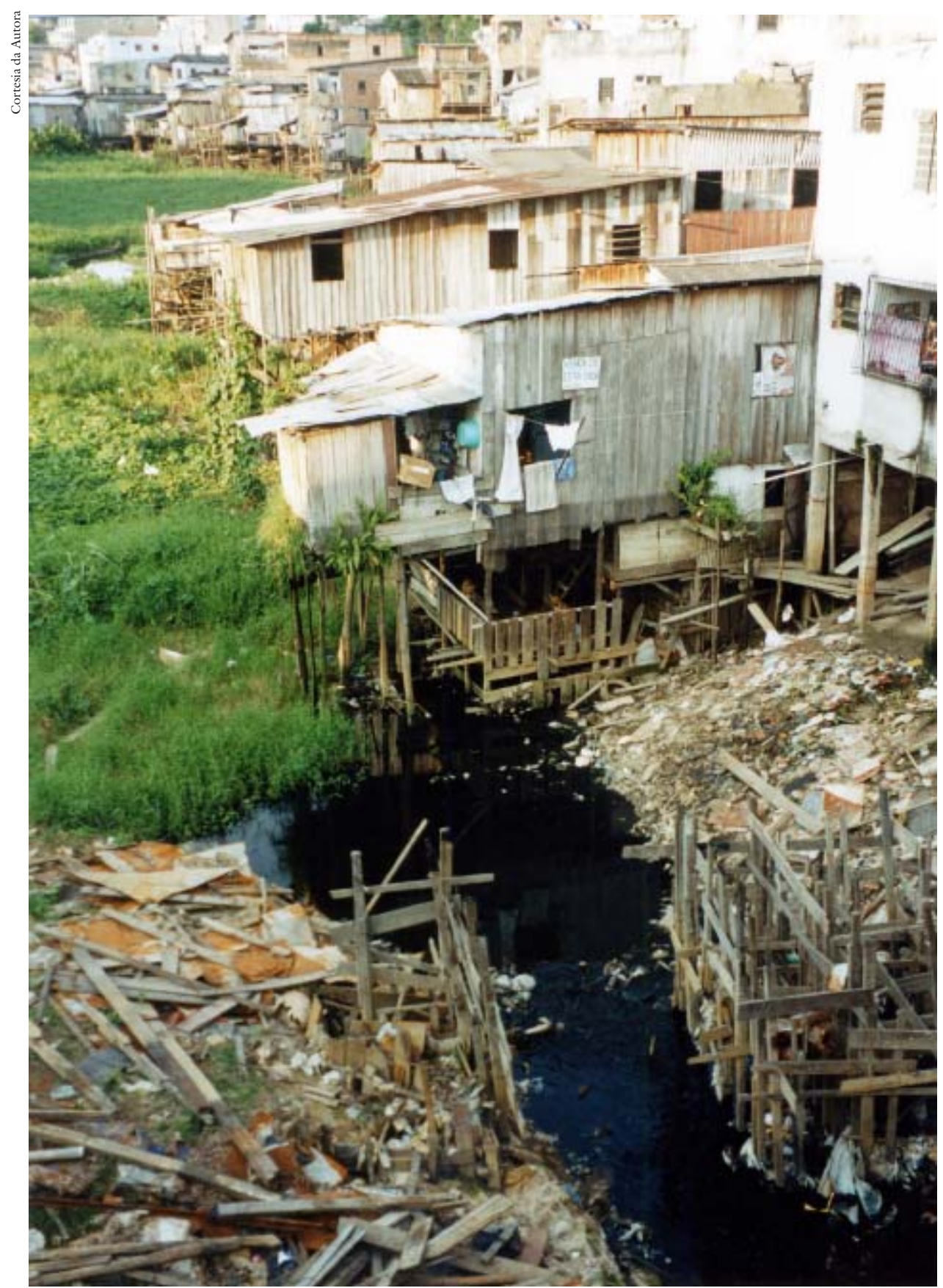

Favela em Manaus (AM) (Fig. 1). 
A elite política e econômica têm se apropriado dessas informações para implementar as suas estratégias de integração geopolitica por meio do modelo de desenvolvimento, com a extração em grande escala de minérios, seixos, ouro, madeira e palmeiras, entre outros, e com a expansão das fronteiras agro-pecuárias. Entretanto, a escala muito pequena traz muitas incertezas, surpresas e até desconhecimento da realidade local, razão pela qual muitas das políticas levaram ao fracasso. Entre as inúmeras dificuldades que surgem na realização do zo-neamento para a região Amazônica está a extensão geográfica e a enorme diversidade ecológica. Para realizar um diagnóstico detalhado de toda a Amazônia, em escala apropriada, seriam necessários recursos muito maiores do que os atualmente disponíveis, além de várias décadas para efetuar os levantamentos.

A partir de 1970, os primeiros levantamentos que deram início aos processos mais recentes de produção de diagnósticos receberam recursos do Banco Mundial. Desde então, os bancos internacionais começaram a exigir a realização de um zoneamento para conceder empréstimos. A principal atenção era dirigida ao levantamento biofísico e ao potencial dos recursos naturais visando à expansão de atividades agropecuárias. Inicialmente, o zoneamento era entendido como ferramenta de auxílio, principalmente no planejamento das atividades produtivas (como no caso do zoneamento agrícola e agroecológico) e compreendia estudos sistemáticos sobre a base de recursos naturais (solo, geologia, geomorfologia, vegetação, clima); aspectos socioculturais e econômicos receberam pouca atenção pelos órgãos executores do zoneamento. A crescente preocupação com o meio ambiente e o reconhecimento da importância dos aspectos ambientais como fatores limitantes ao uso e à produção fizeram os diagnósticos incluírem uma componente ambiental. Fundamentado na Política Nacional do Meio Ambiente (Lei n. ${ }^{\circ} 6.938$ de 31/08/1981), deu-se início ao zoneamento ambiental. Por ter uma orientação teórica com pouco embasamento nas verdadeiras demandas e vontades locais, essa abordagem teve pouco impacto no ordenamento da ocupação na Amazônia (Millikan, 1998).

Em 1981, o Banco Mundial apoiou o projeto Pólo Noroeste, com o objetivo de ordenar o uso do solo nas áreas ocupadas pela frente pioneira em Rondônia e para conter o desmatamento. As duas metas não foram alcançadas. Pelo contrário, o desmatamento continuou até mais descontroladamente, sendo ainda incentivado pelas ações do programa (Mahar \& Ducrot, 1999). Em 1985, iniciou-se o projeto de Proteção do Meio Ambiente e das Comunidades Indígenas (PMACI I e II), coordenado pelo Instituto de Planejamento Econômico e Social (atualmente Instituto de Pesquisa Econômica Aplicada). Seu objetivo principal era orientar a ocupação humana e mitigar os impactos socioambientais decorrentes do asfaltamento da rodovia BR-364 (Cuiabá - Porto Velho - Rio Branco Cruzeiro do Sul). A área abrangida pelos estudos cobre o noroeste de Rondônia, sudoeste do Amazonas e a maior parte do Estado do Acre. Foi realizada uma série de estudos visando ao zoneamento geoambiental da área. O PMACI elabo- 
rou diagnósticos da estrutura e da dinâmica socioeconômica, estudos sobre as pressões das atividades antrópicas, e ainda forneceu subsídios ao plano de orientação (IBGE, 1994). Como resultado, produziu-se um diagnóstico detalhado que, no entanto, não impediu a ocorrência de sérios impactos ambientais resultantes da ocupação nas margens da rodovia e da expansão das atividades agropecuárias, além de ter até incentivado a extração ilimitada dos recursos florestais. Pode-se dizer que, de forma geral, a abertura de qualquer rodovia, com ou sem planejamento, significa impactos diretos sobre a floresta, seja promovendo a exploração seletiva da madeira e o garimpo, seja pelo aumento da ocupação humana e das atividades agropecuárias decorrentes.

$\mathrm{Na}$ seqüência, o governo lançou, em 1988, o zoneamento ecológicoeconômico (ZEE), no âmbito do programa "Nossa Natureza". O objetivo era disciplinar a ocupação e a exploração racionais da Amazônia Legal, fundamentadas no ordenamento territorial. Uma década depois, o ZEE é visto como instrumento capaz de romper as posições polarizadas, oferecendo oportunidades de crescimento econômico e uso dos recursos naturais através da qualidade ambiental (MMASAE, 1997, p. 9). O discurso oficial tem incorporado um forte componente ambiental sem, porém, definir, por exemplo, o que significa qualidade ambiental na prática. Daí para frente, a maioria dos trabalhos segue a metodologia proposta pela Secretaria de Assuntos Estratégicos (SAE) e pelo Laboratório de Gestão Territorial da UFRJ (MMA-SAE 1997).

Durante os anos de 1990, os projetos do ZEE receberam apoio técnico e financeiro do Subprograma de Políticas de Recursos Naturais (SPRN) e do Programa Piloto para a Proteção das Florestas Tropicais no Brasil (PPG7). Em 1999, a SAE foi extinta e a gerência do ZEE na Amazônia passou para a Secretaria de Desenvolvimento Sustentável e a Secretaria de Coordenação da Amazônia dentro do Ministério do Meio Ambiente. Hoje o programa está inserido no Plano Plurianual 2000-2003, e os governos federais e estaduais têm adotado o ZEE como instrumento técnico de informação sobre o território (...) uma ferramenta politica de regulação do uso do território e (...) um instrumento de planejamento e gestão territorial voltado para o desenvolvimento regional sustentável (MMA-SAE, 1997, p. 12). Precisa ser sublinhado que o zoneamento ainda deve estabelecer referências básicas para a preservação e a proteção, visando à preservação da biodiversidade, à manutenção dos serviços ambientais e ao uso sustentável dos recursos naturais.

\section{Impasses e desafios do zoneamento}

Os inúmeros relatos de naturalistas, pesquisadores ou de membros de sociedades tradicionais têm tratado da complexidade do universo amazônico. Estamos apenas conhecendo fragmentos deste universo complexo, desconhecido e caracterizado pela extensão geográfica, diversidade ecológica e história de ocupação e exploração. Durante as entrevistas e discussões sobre a prática da implementação do ZEE, conduzidas em campo, ocorreu uma série de dificuldades e impasses. 


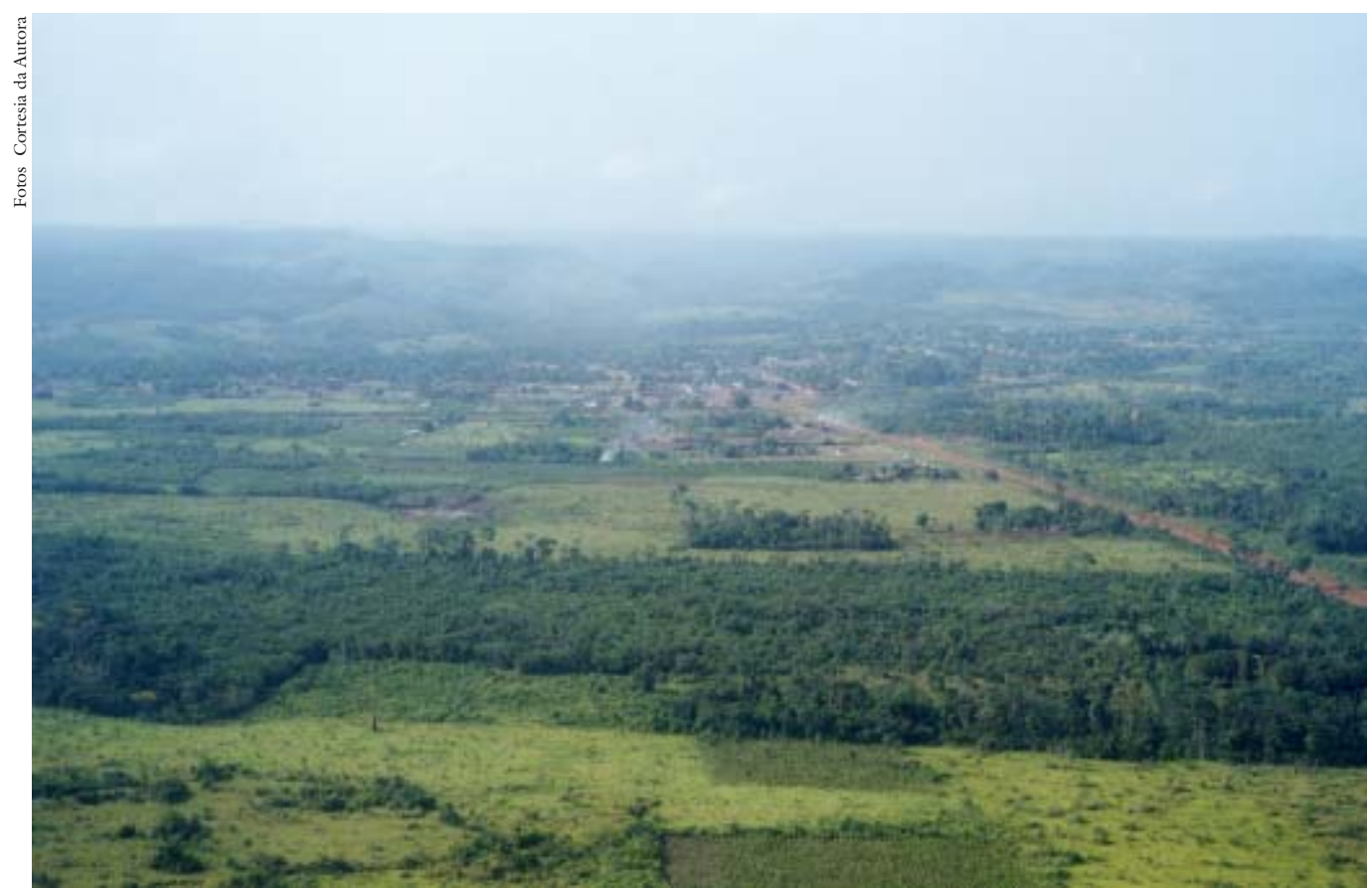

Ocupação agropecuária ao longo da rodovia Transamazônica (Apuí) (Fig. 2).

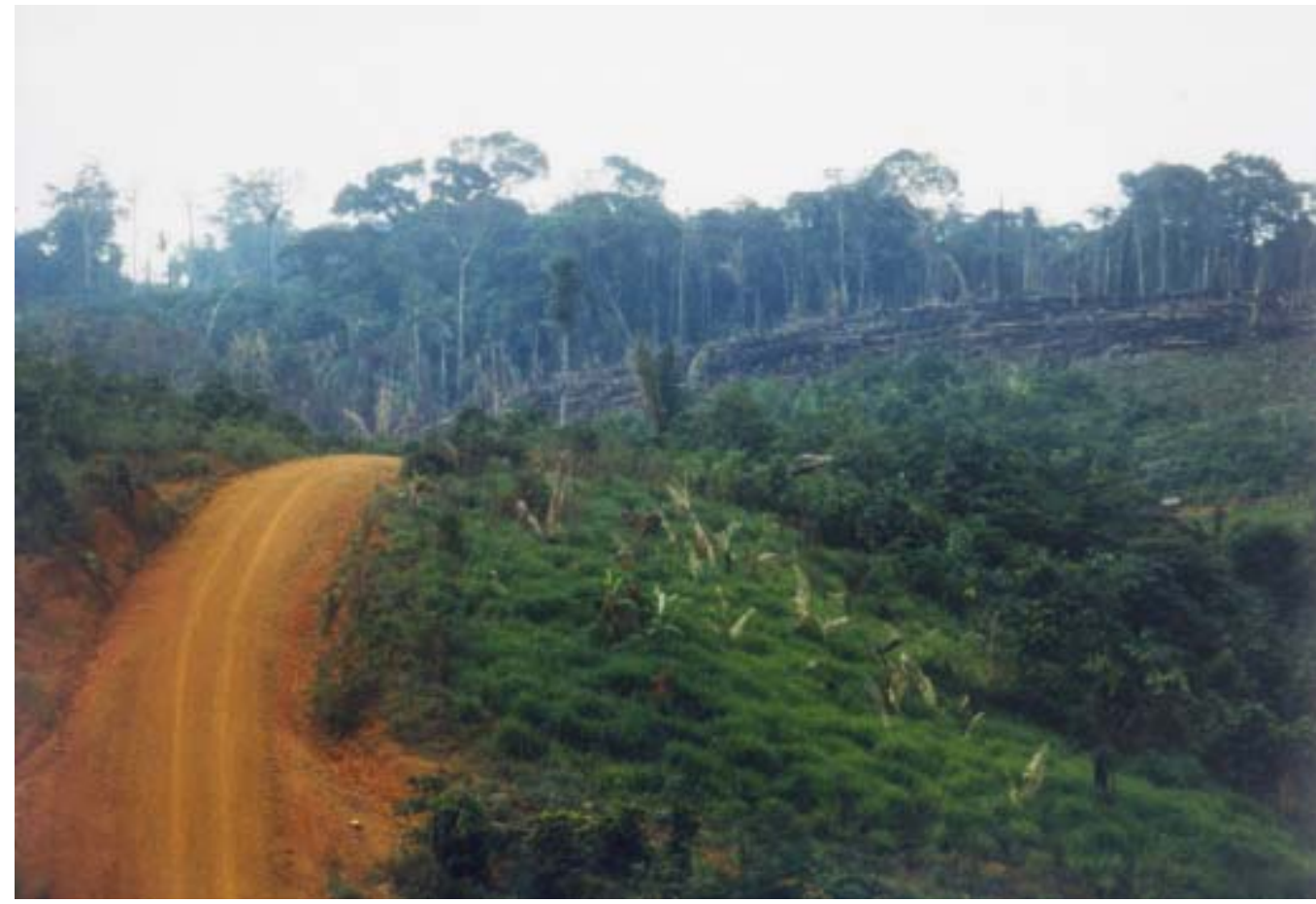

Frente de colonização no municipio de Apui (fig. 3).

O primeiro fator crítico se refere à definição de escalas apropriadas, e que Ab'Sáber $(1996,1989)$ tem reiterado repetidas vezes a sua importância. Os resultados do zoneamento federal (1:3.000.000) têm orientado políticas para o de- 
senvolvimento econômico da região e, na prática, têm subsidiado procedimentos agressivos e insustentáveis considerando uma avaliação de longo prazo. Como exemplos, temos o avanço dos desmatamentos, atualmente ocorrendo em áreas de cerrado na Amazônia, com o objetivo de aumentar a produção de grãos em grande escala (por exemplo, em Humaitá, Marabá e Santarém) ou a expansão dos eixos rodoviários que tem facilitado a penetração de madeireiros e acelerado a especulação imobiliária.

De maneira semelhante, o macrozoneamento estadual (1:1.000.000) permite caracterizar o espaço em escala regional, o que talvez possibilite afirmações e indicações genéricas em relação às características gerais dos Estados e das grandes regiões do país. Para o Estado, o macrozoneamento serve como ferramenta para o planejamento regional. Bem aplicado, ele pode, por exemplo, identificar áreas prioritárias para a criação de unidades de conservação.

Aprendemos que escalas pequenas e generalizadas não permitem retratar a complexidade e a dinâmica socioeconômica e cultural do local. Elas ignoram e mascaram dimensões socioculturais e escondem a presença de fatos pontuais como impactos, riscos ou conflitos. Para as áreas prioritárias do zoneamento, a escala aplicada hoje é de 1:250.000 e, em casos pontuais, de 1:100.000. Mesmo assim, em determinadas áreas o zoom deve ser ampliado mais ainda para subsidiar o planejamento e a tomada de decisões (por exemplo, em áreas periurbanas ou com potenciais diversos como sítios arqueológicos, turísticos ou de possível intensificação da produção; além das áreas que apresentam situações de conflitos, impactos pontuais ou outros usos específicos como atividades extrativistas etc.).

Escalas muito pequenas podem levar a equívocos no prognóstico. Uma área parece desabitada mas, na verdade, faz parte da área de influência de uma comunidade ou é utilizada para abastecer a população, como geralmente é de praxe nas comunidades rurais tradicionais. Um caso semelhante foi descrito por Peluso (1995) no caso dos Dayak na Indonésia. A enorme diversidade social e cultural da Amazônia foi ressaltado por Benchimol (1999). A riqueza e a complexidade sociocultural costumam ser omitadas durante os processos e a formulação de políticas para o ordenamento.

A escala do macrozoneamento tampouco permite caracterizar a cobertura de floresta entre natural alterada e não-alterada. O grau de alteração, por exemplo, por corte seletivo, não pode ser identificado nessa escala. Portanto, o mapa de vegetação pode camuflar o verdadeiro grau de degradação da cobertura vegetal natural.

Além do equívoco com a escala, também existem problemas cartográficos. Identificaram-se dificuldades com a interpretação da informação contida nos mapas, como os da Embrapa. As legendas geralmente são técnicas e sua linguagem precisa ser traduzida para que o leitor comum possa apropriar o conhecimento. Por outro lado, o mapa precisa conter as informações necessárias para o 
reconhecimento local, por exemplo, ter dados a respeito da ocupação humana, infra-estrutura, rios etc., para que o leitor consiga se inserir no espaço apresentado e, portanto, o mapa tenha significado para ele.

Uma segunda questão crucial para o desenvolvimento sustentável é garantir uma ampla participação. Diga-se desde já que esta também é a questão mais polêmica e difícil de pôr em prática, uma vez que significa discussões e resoluções de conflitos entre agentes com interesses muitas vezes antagônicos (GTZ 1992). O número crescente de iniciativas visando à integração entre poder público, poder econômico e sociedade civil na discussão sobre planejamento e desenvolvimento prova que participação é um pré-requisito fundamental neste processo. As experiências com agências, fóruns, comitês, conselhos etc. estão se multiplicando no país. É certo que nem todas essas experiências são bem-sucedidas e não conseguem alcançar os objetivos aspirados. No entanto, é um processo necessário que amplia o conhecimento e a consciência dos participantes e, desta forma, contribui para a construção da cidadania.

Até o presente momento, houve pouca participação da sociedade civil na elaboração dos diagnósticos para o zoneamento. A metodologia aplicada pelas equipes executoras para os levantamentos temáticos não tem envolvido de forma sistemática os representantes da população local. Tampouco houve, no início dos trabalhos, uma ampla discussão nas comunidades sobre os objetivos do ZEE e os fins e métodos dos levantamentos temáticos. Por causa dessa omissão, é muito mais difícil agora fazer a população se apropriar do conhecimento gerado pelo diagnóstico. Conseqüentemente, será mais demorado envolvê-la em discussões acerca de planejamento, manejo e gestão dos recursos naturais nas suas comunidades ou municípios.

Uma terceira questão que precisa de solução está relacionada com a nãoregularização fundiária nos municípios e a pouca sistematização desses dados. Este fato está impossibilitando a realização de um planejamento da ocupação do espaço. O Incra, principal órgão encarregado para a regularização fundiária, não atua na revisão da situação das terras na Amazônia desde a década de 1980. Até hoje a falta de informação detalhada continua e, apesar de o ZEE ter estabelecido parcerias para a regularização fundiária nos vários Estados, esses dados ainda não estão disponíveis. Em muitos municípios, continuam a invasão e a exploração irregular de recursos naturais em terras indígenas, áreas de proteção e unidades de conservação. Além disso, ainda é necessário uma revisão da legislação fundiária e agrária nos Estados. A tomada de qualquer decisão a respeito de "ordenamento" e "reordenamento territorial" passa pelo reconhecimento da situação fundiária. A falta desta base de dados compromete o diagnóstico e a análise para o prognóstico, além de, muitas vezes, até inviabilizar a implementação das ações propostas.

Por fim, precisa ser chamada a atenção para a pouca valorização do conhecimento local das populações tradicionais da Amazônia. Segundo Christine Scheibe Wolff(1999, p. 106), elas têm um "conhecimento aprofundado da natureza e de 
seus ciclos, que se reflete na elaboração de estratégias de uso e de manejo dos recursos naturais. Esse conhecimento é transferido de geração em geração por via oral". Não existe ainda uma sistematização das informações de pessoas portadoras deste rico conhecimento, pois elas são transmitidas por mateiros ou extrativistas da região e não são registradas, por não serem consideradas conhecimento acadêmico. Os levantamentos florísticos e pedológicos para o zoneamento, por exemplo, são geralmente acompanhados por mateiros ou guias que têm um conhecimento profundo da região. Eles podem identificar na área onde há sítios arqueológicos, áreas de exploração e extração ilegal (mineração de seixos, areia, ouro etc.), desmatamentos, pontos de tráfico de drogas, e outros impactos e locais de conflitos ambientais e sociais. Além disso, eles possuem conhecimento popular sobre a fauna e a flora amazônicas. Não obstante, os diagnósticos até agora produzidos não refletem a incorporação do conhecimento local e, lamentavelmente, muitos dados são perdidos.

\section{A quem serve o zoneamento?}

Até hoje, apenas Rondônia, Amapá e Acre tiveram seu diagnóstico concluído para todo o seu território. No caso de Rondônia, produziu-se em quase dez anos uma sala cheia de relatórios e muitos megabytes de bancos de dados que, porém, ainda não são acessíveis ao público. De maneira geral, não houve participação da população no levantamento de dados, razão pela qual a aceitação do ZEE pelo público também foi baixa. Nos outros Estados, estão à disposição apenas dados parciais do levantamento do ambiente físico, como a informação sobre a qualidade dos solos, a aptidão agrícola ou o potencial madeireiro.

$\mathrm{Na}$ realidade, as informações já disponíveis estão subsidiando políticas e ações econômicas e de desenvolvimento regional. A setorização na avaliação dos recursos ecológicos pode levar a sérios equívocos. Ab’Sáber (1996, p. 12) alerta para o fato de o estabelecimento puro e simples de uma carta das classes de capacidade do solo poderia induzir os especuladores e os administradores mal avisados a cometer as propostas agrárias mais absurdas. Ele continua lembrando que a própria cartografia extensiva do Projeto Radam, dirigida para o uso potencial dos solos, tem se mostrado ineficiente e perigosa, quando utilizada com rigidez, favorecendo as mais diversas distorções pelos interessados no uso empirico dos espaços amazônicos. Particularmente o diagnóstico biofísico muitas vezes é compreendido como uma ferramenta útil para identificar recursos naturais e potencialidades para a sua exploração, servindo aos madeireiros e agropecuaristas muito mais do que à comunidade local. Este fato levanta questionamentos como: quais são os reais objetivos do zoneamento e a quem servem os seus resultados? O ZEE está realmente contribuindo na reversão do desenvolvimento irracional e na promoção de sociedades sustentáveis? Até que ponto o ZEE exerce uma função de mero instrumento de convalidação da hegemonia existente em termos de desenvolvimento econômico? 
Pode-se concluir que, até o presente momento, o processo do ZEE não conseguiu anteceder nem acompanhar a dinâmica local de "desenvolvimento" nos Estados estudados nesta pesquisa. As transformações ambientais e sociais ocorrem de forma tão rápida que os levantamentos já se tornam ultrapassados antes mesmo de terminados. A dinâmica do desenvolvimento regional também é alimentada por processos migratórios, impactos ambientais cumulativos e conflitos socioeconômicos. No entanto, a metodologia aplicada até o presente não conseguiu captar essa dinâmica. Pelo contrário, o diagnóstico torna acessível informações importantes sobre o potencial biofísico como aptidão agrícola, potencial produtivo (muitas vezes até promovendo simulações para certos cultivos agrícolas), recursos minerais, potencial florístico, tipo de infra-estrutura existente e/ou planejada etc., facilitando a sua exploração. Além disso, uma leitura desagregada dos indicadores socioeconômicos e culturais pode levar a conclusões e propostas equivocadas para o desenvolvimento.

Existe o risco de grupos de influência econômica e política (corporações, empresas, bancos e agências de financiamento) e/ou poder político se apropriarem da informação, ou de parte da base de dados disponibilizados pelo diagnóstico, para promover seus interesses particulares. Em muitos dos municípios localizados próximo ao "eixo de desenvolvimento" e das áreas de expansão da produção de grãos já se iniciou um forte processo de especulação, com as comunidades rurais em retração e o capital proveniente de Mato Grosso e de outros especuladores do Sul do país em avanço (como se observa, por exemplo, na microbacia do Mojuí, nos municípios de Santarém ou de Marabá). Semelhantes observações podem ser feitas em relação ao avanço da pecuária extensiva.

Nem sempre a perspectiva federal de desenvolvimento regional e os interesses do Estado e do município estão em consenso. O governo federal, por exemplo, continua promovendo o desenvolvimento centralizado e de grande escala, como é o caso das políticas para a promoção dos eixos de desenvolvimento no âmbito do Programa Avança Brasil. O modelo de desenvolvimento em questão não considera as necessidades e demandas das comunidades locais nem contempla possíveis soluções e projetos alternativos com menor impacto ambiental e maior benefício social. Até agora o ZEE é entendido principalmente como um instrumento para o desenvolvimento de cima para baixo, com baixa participação popular e pouco considerando as necessidades e realidades vividas no município e nas comunidades.

Como podem ser ajustados esses impasses: os problemas com a escala e a extensão do espaço, a setorização da informação e a falta de participação da comunidade? Em primeiro lugar, é necessário trabalhar o nível municipal e local de forma participativa, por meio de uma sistematização das informações aplicando critérios e indicadores para a sustentabilidade. Esta metodologia focaliza as questões prioritárias para o ordenamento, seja para mitigar impactos ambientais, resolver conflitos sociais, criar áreas de proteção ou de conservação, seja para in- 
centivar a produção agrícola, agroflorestal ou florestal etc. (veja os resultados do projeto CIAT-Unep, Dalal-Clayton, 1993, ed. GTZ , 1995, 1992; ou MacGillivray et al., 1998).

A seguir, serão apresentados alguns dos passos importantes na realização de um planejamento mais participativo e da conseqüente co-gestão.

\section{Uma abordagem participativa para a Amazônia}

Fala-se muito em desenvolvimento sustentável, porém pouco se sabe de sua prática. Antes de mais nada, é necessário definir o conceito da sustentabilidade e explicitar a sua aplicação no âmbito do zoneamento. É preciso definir critérios e indicadores que servirão de pré-requisitos para orientar e indicar formas sustentáveis de ocupação do espaço e de uso dos recursos naturais, que auxiliam no monitoramento dos seus impactos e benefícios. Uma vez definidas, essas informações são introduzidas num amplo debate, para que possam servir de subsídio para a elaboração de políticas públicas em todos os níveis de governo.

O discurso político evita as aparentes contradições em torno do conceito da sustentabilidade. Os relatórios, documentos oficiais e discursos são enfeitados com esta palavra mágica; na prática, porém prevalece a prioridade econômica (que, de praxe, é sustentável apenas para poucos). Como premissa inicial, é importante ampliar o debate sobre o tema e discutir o significado de sustentabilidade em relação à produção, ao consumo, uso e ocupação de espaços. Como alcançar sustentabilidade econômica, ecológica, social e cultural ao mesmo tempo? É preciso refletir sobre o conceito não apenas como uma construção teórica, mas aplicálo na prática, por exemplo, em processos participativos de gestão e manejo ambiental. Uma gestão com essas características envolve a promoção de atividades de preservação, produção, extração ou, ainda, de prestação de serviços naturais até hoje não contabilizados e não pagos como capatação de gás carbônico, regime hidrológico, fertilidade dos solos, fixação de nitrogênio, polinização e controle biológico de pragas, ou pelos atrativos naturais do ecoturismo.

Se a nossa intenção for questionar e desafiar o status quo, é necessário trabalhar a capacidade de produção de conhecimento e atuação em nível local. Isto também inclui a participação de agentes de outras esferas como o governo estadual, as universidades, as ONGs regionais etc. A proposta metodológica para promover o ordenamento e a gestão local (microbacia hidrográfica, município, comunidade), aqui defendida, compreende basicamente quatro componentes diferentes: articulação política, diagnóstico, prognóstico e implementação.

- A articulação política no município começa com a identificação e a mobilização das lideranças e representações dos diferentes grupos sociais no município.

- O diagnóstico nada mais é que um atual retrato sistematizado da situação local, no que diz respeito aos seus principais problemas sociais e ambientais, 
os potenciais e recursos, assim como as experiências bem-sucedidas. Aproveitam-se as informações já existentes.

- O prognóstico é um amplo processo de divulgação de informação, proposição, avaliação e negociação entre os atores interessados. Já possuímos muitas informações sobre a Amazônia, porém, o conhecimento fica acumulado nas bibliotecas (principalmente na Europa e nos Estados Unidos) e nas unidades acadêmicas e de pesquisa; dificilmente chega à localidade. As comunidades ficam excluídas das informações que, muitas vezes, lhes poderiam ser úteis, por exemplo, sobre sistemas de produção, novas tecnologias ou certificação de produtos e processos. Portanto, a transferência do conhecimento para o nível local precisa ser garantida.

A orientação básica para a tomada de decisões em relação ao uso e não-uso dos recursos naturais deveria estar baseada em critérios e indicadores para a sustentabilidade. A sociedade civil precisa internalizar e assumir o processo para garantir a manutenção de áreas de proteção, melhorar o uso dos recursos e ordenar a ocupação do espaço. Por isso, a importância de fortalecer o trabalho na base. Já existem experiências na aplicação de critérios e indicadores no processo de geração e aplicação de conhecimento (Pokorny, Steinbrenner \& Nunes, 2000).

- Os órgãos que vão atuar na implementação precisam estar presentes e devem participar das discussões desde o início do processo. A comunidade científica tem um papel importante na elaboração de proposições para sistemas de manejo sustentável dos recursos naturais e métodos de recuperação de áreas degradadas. É necessário traduzir os resultados de pesquisas para uma linguagem popular e acessível.

- Por fim, o monitoramento é um processo constante e permite a readequação dos passos da metodologia. Verificadores servem para dar um feedback de médio a longo prazo das ações e atividades implementadas. Eles também facilitam a adequação e adaptação das ações e atividades a circunstâncias novas e variadas.

Já existem algumas experiências isoladas nas quais a população local teve maior envolvimento nas discussões e nos levantamentos da situação socioambiental no município. Por exemplo, estão sendo realizadas reuniões no PGAI municipal com o objetivo de ouvir e envolver a sociedade civil organizada (oficinas em Novo Aripuanã e Manicoré no Amazonas, em Itaituba ou nos municípios do lago do Tucuruí, no Pará). Também foram realizadas discussões sobre orçamento participativo (por exemplo, em municípios do Acre) e está sendo elaborada e testada, ainda de forma tímida, uma proposta para o microzoneamento no Amapá. Além disso, ainda serve de experiência positiva e inspiradora a elaboração de planos de manejo participativo mencionada anteriormente. Contudo, é importante notar que esta abordagem participativa partindo do nível local precisa de continuidade e exige perseverância e vontade política de todos os níveis. 
Cabe ainda ao nível federal o engajamento na discussão sobre critérios e indicadores para a sustentabilidade, visando direcionar melhor os recursos e as políticas públicas para o desenvolvimento sustentável e a conservação. Entre as prioridades na esfera nacional, colocam-se as seguintes questões:

- Estabelecimento de linhas de crédito para o uso e manejo sustentável dos recursos (neste contexto precisam ser definidos os critérios e indicadores que definem o que é sustentável).

- Criação e consolidação de Unidades de Conservação e demarcação de terras indígenas.

- Investimento em infra-estrutura seguindo os critérios e indicadores para a sustentabilidade.

- Levantar a discussão em torno da valorização econômica dos serviços ambientais da floresta nos níveis nacional e internacional.

- Agilizar ações para pôr em prática a valorização econômica dos serviços ambientais da floresta e facilitar a distribuição dos arrecadamentos para os municípios e indivíduos.

- Promover educação e conscientização ambiental, capacitação técnica, pesquisa e desenvolvimento tecnológico adequado.

- Fomentar políticas públicas e programas para a produção sustentável nos níveis federal e estadual, como:

- certificação de linhas de produtos provenientes de atividades sustentáveis;

- linhas de crédito para uso e manejo sustentável;

- ICMS ecológico, entre outros.

\section{Considerações finais}

As políticas e estratégias adotadas até o presente para o planejamento territorial na Amazônia precisam ser revisadas e reorientadas, para serem efetivas e eficientes na implantação de alternativas de desenvolvimento. É necessário envolver a comunidade local por meio de estruturas mais democráticas como fóruns de discussão e conselhos (p. ex., com grupos temáticos de trabalho). As estratégias convencionais de desenvolvimento - cuja análise e prognóstico estão fundados numa lógica cartesiana, seccionada, e cuja estrutura de implementação continua sendo centralizadora e de cima para baixo - não atendem às exigências do desenvolvimento sustentável. Se o objetivo é não apenas o discurso mas sim a prática, precisamos resolver localmente os problemas da perda da biodiversidade, do desmatamento, do aumento da erosão, da contaminação da água, do aumento da exclusão social e da violência no campo, além de toda a gama de problemas socioambientais que ocorrem nas cidades e que nos últimos anos têm aumentado drasticamente. 
No presente artigo foi discutida uma abordagem participativa para o microzoneamento, envolvendo a comunidade local a partir da articulação e diagnóstico até a discussão do prognóstico e a implementação e o monitoramento. Alternativas para o desenvolvimento precisam ser conhecidas e entendidas pelos atores. O desenvolvimento já está acontecendo em nível local, porém, em geral, não de maneira sustentável. Os municípios na Amazônia estão hoje sofrendo impactos ambientais e sociais que exigem uma resolução rápida para o bem não apenas das populações locais, mas também para a humanidade como um todo. Nós não podemos mais dar o luxo de perder e desperdiçar recursos naturais, como tem acontecido com a floresta, mas sim devemos procurar melhores formas de aproveitamento da riqueza presente neste bioma.

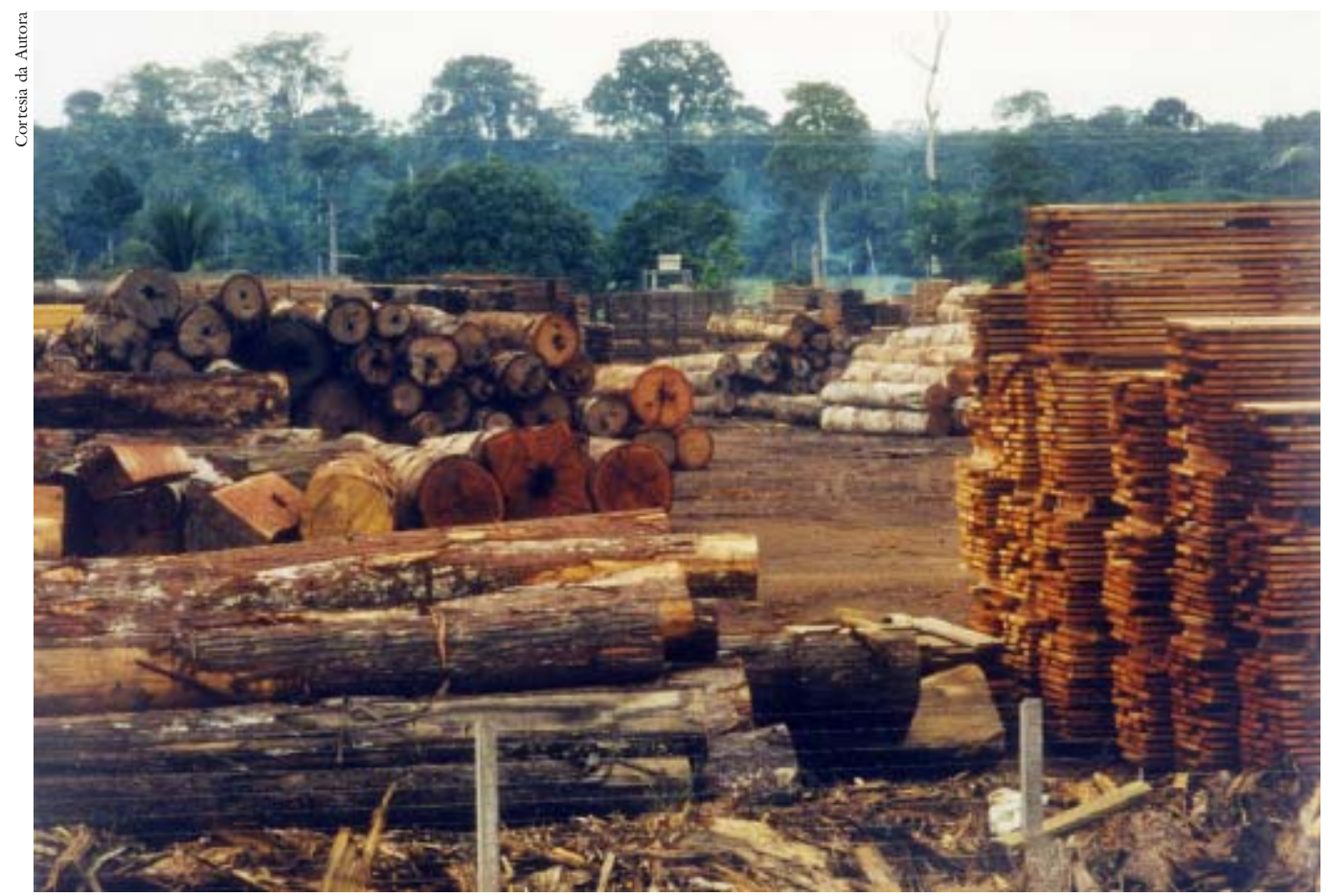

Há desperdício de recursos ao invés de objetivar o ganbo com a floresta em pé (fig. 4).

Em 2000, foram realizadas em Apuí, no Amazonas, várias oficinas municipais para implementar o Plano de Gestão Ambiental Integrada. Um dos objetivos foi a realização de um zoneamento participativo. Nesta oficina participaram o prefeito, agentes ambientais do município e do Estado, produtores rurais e até madeireiros. Durante a reunião foram levantadas preocupações com a falta de conscientização da população, bem como a falta de informação para o agricultor sobre a proteção ambiental, o manejo adequado, as alternativas de uso e, ainda, a falta de descontinuidade de projetos, o que cria descrença e desestimula a participação. Também foi questionado o que fazer com as áreas degradadas e quais seriam as alternativas de produção para o município. Foi indicado como proble- 
ma a falta de informação sobre culturas alternativas e possibilidades de escoamento da produção, assim como melhores formas de comercialização.

Este é o quadro típico encontrado em áreas com predominância de pequena produção. É notável a carência de informações sobre alternativas de produção. Em outro município, Presidente Figueiredo, que tem uma vocação para o turismo ecológico, as questões levantadas estão relacionadas com a criação da área de proteção ambiental e formas para fomentar atividades relacionadas ao turismo. Essas são as realidades que o zoneamento precisa conhecer (e não conhecerá com os levantamentos na escala de 1:1.000.000). É este tipo de preocupação que precisa ser levado em consideração ao implementar o desenvolvimento sustentável.

Demandas, pressões e conflitos acontecem localmente. É aí que ocorre o desmatamento, a perda da biodiversidade e a desintegração e exclusão social. Para que as medidas do governo realmente possam reverter essa situação, elas precisam "descer” para o nível local na procura e implementação de soluções. É certo que este trabalho necessita de estruturação e organização, para não deixar a burocracia, a corrupção, a ganância e a falta de comprometimento tomar conta do processo. É necessário criar estruturas participativas e transparentes para poder exercer o controle de qualidade. Não existe a solução para a Questão Amazônica, mas é preciso avaliar as atuais práticas e políticas públicas e sugerir novas formas de abordagem para os inúmeros problemas socioeconômicos e ambientais que a região vive atualmente. Ressalta-se o fato de que as propostas mencionadas aqui são idéias que vêm se cristalizando e realidades que cada vez mais vêm se impondo em diversos locais no Brasil.

Bibliografia

AB'SÁBER, A. N. Amazônia, do discurso à praxis. Edusp, São Paulo,1996.

AB'SÁBER, A. N. “Zoneamento ecológico e econômico da Amazônia”, in Revista do Instituto de Estudos Avançados. USP, São Paulo, 3 (5), 1989, p. 4-20.

ALMEIDA, R. et al. "A experiência da floresta nacional do Tapajós Ibama/Santarém, Pará", in Anais da Oficina sobre gestão participativa em unidades de conservação. Fundação Biodiversitas, Maria Auxiliadora Drumond, Belo Horizonte, 1998, p. 107-20.

BENCHIMOL, S. Amazônia, formação social e cultural. Valer Editora, Manaus, 1999.

BROWDER, J. D. e GODFREY, B. J., Rainforest cities. Urbanization, develoment and globalization of the Brazilian rainforest. Columbia University Press, Nova York, 1997.

CIAT-UNEP. "Environmental and sustainability indicators. Outlook for Latin America and the Caribbean". Centro Internacional de Agricultura Tropical \& United Nations Environmental Program, Cali (http://www.ciat.cgiar.org/indicators/lacproj.htm).

DALAL-CLAYTON, D. B. Modified EIA and indicators of sustainability: first steps towards sustainability analysis. Environmental Planning Group, International Institute for Environment and Development, Londres, 1993, 12 p. 
GTZ (ed.) Landnutzungsplanung: Strategien, Instrumente, Methoden. Arbeitsgruppe Integrierte Landnutzungsplanung, Eschborn, 1995.

GTZ (ed.) Cuando la participación falta... Eschborn, 1992.

HALl, A. Amazônia: desenvolvimento para quem? Desmatamento e conflito social no Programa Grande Carajás. Jorge Zahar Editor, Rio de Janeiro, 1991.

IBGE (Fundação Instituto Brasileiro de Geografia e Estatística). Diagnóstico geoambiental e socioeconômico. IBGE: Diretoria de Geociência \& Instituto de Pesquisa Econômica Aplicada. Rio de Janeiro, 1994.

MACGILLIVRAY, A., WESTON, C. \& UNSWORTH, C. Communities count! A step by step guide to community sustainability indicators. Londres: New Economics Foundation, 1998, $163 \mathrm{p}$.

MAHAR, D. J. \& DUCROT, C. E. H. "Land-use zoning on tropical frontiers. Emerging lessons from the Brazilian Amazon", in Economic Development Institute of the World Bank. EDI Case Studies, 1999, p. 1-25.

MILLIKAN, B. H. Zoneamento sócio-econômico-ecológico no Estado de Rondônia. Análise de um instrumento de ordenamento territorial na fronteira amazônica, Projeto BRA/94/007 (PNUD/Planafloro) (documento não publicado), 1998.

Ministério do Meio Ambiente, Secretaria de Assuntos Estratégicos. Detalhamento da metodologia para execução do zoneamento ecológico-econômico pelos Estados da Amazônia Legal. Brasília, 1997.

Ministério do Meio Ambiente, Secretaria de Biodiversidade e Florestas. Consulta nacional sobre critérios e indicadores de sustentabilidade da Floresta Amazônica no âmbito do processo de Tarapoto. Belém (documento não publicado), 2000.

PELUSO, N. L. "Whose woods are these? Counter-mapping forest territories in Kalimantan, Indonesia". Antipode, 27 (4), 1995.

POKORNY, B., STEINBRENNER, M. \& NUNES, W. Relatório sobre o teste da "oficina de atores" da metodologia ZEE participativo baseado em C \& I., Paragominas, 18.10.2000 (documento não publicado).

REIS, M. Batista. "Reserva de desenvolvimento sustentável Mamirauá (RDSM) Amazonas, Brasil", in Anais da Oficina sobre gestão participativa em unidades de conservação. Fundação Biodiversitas, Maria Auxiliadora Drumond, Belo Horizonte, 1998, p. 60-69.

RUEDA, R. Pinzón. "Gestão participativa nas reservas extrativistas", in Anais da Oficina sobre gestão participativa em unidades de conservação. Fundação Biodiversitas, Maria Auxiliadora Drumond, Belo Horizonte, 1998, p. 121- 32.

SCHEIBE Wolff, C. Mulheres da floresta: uma história. Editora Hucitec, São Paulo,1999.

Jutta Gutberlet é professora-doutora em Geografia na Universidade de Victoria, Canadá. O presente trabalho foi subsidiado pela experiência de campo adquirida pela autora durante a consultoria no projeto GTZ/PPG7/SPRN, em 2000. A autora agradece a Denise Baena pela sua leitura crítica do artigo. 